\title{
Veterinary Parasitology - recent developments in immunology, epidemiology and control
}

\author{
Edited by RICHARD J. MARTIN AND HENK D. F. H. SCHALLIG \\ Co-ordinating EDITOR L. H. CHAPPELL
}

\section{Preface}

There have been important developments in the field of veterinary parasitology over the last few years. This symposium was called to collect individuals together, who have made significant contributions to their field of study, to present and summarize their work.

I would like to pause for a moment before introducing the Symposium in this preface to comment on the sad loss of Professor Peter Nansen, a particularly eminent Danish scientist who developed our field of study. I, like many others, remember him with affection. He was a very helpful colleague and outstanding leader of the Danish Centre for Experimental Parasitology, Royal Veterinary and Agricultural University, Frederiksberg C. We are all saddened by his death and will continue to carry our memories of him with us.

In the symposium Henk Schallig and I wanted to show how epidemiology is now an important contributor to veterinary parasitology so we were fortunate to get Harm Ploeger to contribute a paper on Dictyocaulus viviparus. We also wanted to review progress in the development of vaccines for the control of parasites: for this we thank Jackie McKeand and David Knox for their contributions. Immunology is also a major component of the science of veterinary parasitology, and we thank Jozef Vercruysse for this contribution. I thank Henk for his review of $H$. contortus immunology. Protozoa are also very significant parasites of domestic animals and Ely Katunguka-Rwakishaya delivered a paper for Peter Holmes which reviewed the importance of nutrition for the survival of animals infected with bovine trypanosomiasis. I have reviewed electrophysiological studies of anthelmintic resistance, and Frank Jackson and Bob Coop have reviewed anthelmintic resistance in sheep. Developments in the diagnosis of ruminant gastrointestinal worms were reviewed by Marten Eysker. Two reviews, on the recent developments on control, were given: Michael Larsen, on predacious microfungi and Sandy Trees on the chemotherapy of onchocerciasis.

The meeting was supported by Pfizer Central Research, Fort Dodge and the British Society for Parasitology. We acknowledge this support gratefully. Both Pfizer and Fort Dodge have continued to support the discipline of veterinary parasitology.

A joy of meetings of veterinary parasitologists is the camaraderie that exists. It is not found to the same level in other life science subjects. I carry good memories of the meeting and thank both the audience and the contributors for the success of the meeting. Time will tell how useful the publications prove to be. Henk and I hope that you will find them to be a useful summary of recent developments in our field.

Richard J. MartiN December 1999 